\title{
Diagnosis and Risk Factors for Delirium in Elderly Patients in the Emergency Rooms and Intensive Care Unit of the National Geriatric Hospital Emergency Department: A Cross-Sectional Observational Study
}

\author{
Nguyen Ngoc Tran' \\ Thi Phuong Nam Hoang ${ }^{2,3}$ \\ Thi Kim Thanh $\mathrm{Ho}^{4}$ \\ 'Department of Psychiatry, Ha Noi \\ Medical University, Ha Noi, VietNam; \\ ${ }^{2}$ Department Geriatrics, Hanoi Medical \\ University, Ha Noi, VietNam; ${ }^{3}$ National \\ Geriatric Hospital, Ha Noi, VietNam; \\ ${ }^{4}$ Department of Family Medicine, Ha Noi \\ Medical University, Ha Noi, VietNam
}

Correspondence: Thi Phuong Nam Hoang

Department Geriatrics, Hanoi Medical University, Ha Noi, VietNam

Email Hoangphuongnam@hmu.edu.vn
Purpose: To diagnose delirium and identify risk factors for its development in elderly patients in the emergency department (ED) and intensive care units (ICU) at the National Geriatric Hospital (Vietnam).

Patients and Methods: A cross-sectional observational study was conducted with a convenience sample of non-surgical patients admitted to ED and ICU at Hanoi National Geriatric Hospital in Vietnam. In total, 163 patients met the selection criteria and were included in the study. Screening involved using the Confusion Assessment Method (CAM) and the Confusion Assessment Method for the Intensive Care Unit (CAM-ICU). The diagnosis was established according to the DSM-5 and ICD-10 codes.

Results: Delirium was found in a total of $106(63.1 \%)$ patients. The factors significantly affecting its development were vision impairment (OR, 3.3; 95\% CI, 1.5 to $7.4, \mathrm{P}=0.003$ ), hearing impairment (OR, 3.6; 95\% CI, 1.77 to $7.36, \mathrm{P}=0.0001)$, acute or chronic kidney failure (OR, 7.1; 95\% CI, 2.05 to $6.39, \mathrm{P}<0.001)$, respiratory disorders (OR, 2.7; 95\% CI, 1.4 to $5.2, \mathrm{P}=0.004)$, and malnutrition ( $\mathrm{OR}, 9.17 ; 95 \% \mathrm{CI}, 3.43-24.5, \mathrm{P}=0.0001)$. The list also include the fall risk factors $(\mathrm{OR}, 12.2 ; 95 \% \mathrm{CI}, 4.1-36.3, \mathrm{P}=0.0001)$, frailty $(\mathrm{OR}, 8.35 ; 95 \%$ CI, 3.4-20.6, $\mathrm{P}=0.0001$ ), activities of daily living (OR, 8.35; 95\% CI, 3.4-20.6, $\mathrm{P}=0.0001$ ), hyponatremia (OR, 2.48; 95\% CI, 1.07 to $5.75, \mathrm{P}=0.001)$, hypernatremia (OR, 13.1; 95\% CI, 1.67 to $2.5, \mathrm{P}=0.001)$, and treatment interventions. In addition, delirium was linked to the duration of ICU admission (OR, 6.53; 95\% CI, 4.5-25.5, P < 0.0001).

Conclusion: The CAM/CAM-ICU diagnostic algorithm makes it possible to diagnose delirium successfully. The present study confirmed the role of several premorbid and triggering factors in the occurrence of delirium in elderly patients in ED and ICU. There is a need for further research into risk factors for delirium in elderly patients.

Keywords: delirium, diagnosis, elderly adult patients, emergency department, risk factors

\section{Introduction}

Over the past few years, the problem of conscientious disorders in the emergency department (ED) and intensive care units (ICU) has received increasing attention. The literature indicates that the incidence of delirium in patients is $20-40 \%$ in ICU and 60 $80 \%$ in ventilated patients. ${ }^{1-4}$ In older patients, the incident rate increases considerably. ${ }^{5,6}$ 
According to some anesthesiologists, the primary challenges of ICU delirium treatment associate with two conditions. $^{7}$ Those are encephalopathy and acute nonspecific psychosis. However, many ED and ICU practitioners are not familiar with this issue and do not draw a precise distinction between delirium, postoperative cognitive dysfunction, and dementia. However, delirium cannot be aligned with postoperative cognitive impairments because it has symptoms that the latter does not have. Examples are disorientation, perceptual deception and cyclical symptomatology. ${ }^{8}$ Delirium should not be confused with dementia as consciousness in dementia is "not clouded" unlike delirium. $^{9}$

The 10th revision of the International Statistical Classification of Diseases and Related Health Problems (ICD-10) defines delirium as an etiologically nonspecific organic cerebral syndrome characterized by concurrent disturbances of consciousness and attention, perception, thinking, memory, psychomotor behaviour, emotion, and the sleep-wake schedule. The duration of the illness varies, and the severity ranges between moderate and severe. ${ }^{10}$

Delirium is probably not an independent disease and cannot have one universal cause for its occurrence. A generally acknowledged model of delirium implies the presence of predisposing and triggering factors. ${ }^{11,12}$ Predisposing factors include age, comorbidities, infections, eating disorders, poisoning, withdrawal syndrome, hearing loss, poor vision, language barriers, etc. In $50 \%$ of senior patients with delirium, the predisposing factors are stroke, Parkinson's disease, or dementia. ${ }^{13,14}$ The triggering factors usually include surgical operations and diagnostic procedures, ICU treatment, drug use, pain, patient fixation, use of urinary catheters, emotional stress, and prolonged absence of sleep.

The risk of delirium may be due to the interaction of predisposing and initiating factors, and, according to the circumstances, the initiating factors may act as predisposing and vice versa.

Delirium is a factor increasing the time patients spend on a ventilator and in the intensive care unit. Hence, it increases treatment costs. Delirium also raises the risk of a lethal outcome, that is, by $10 \%$ each day 5 . Note that delirium often causes cognitive impairment that persists for months to years after intensive care. In addition, patients may not be able to recover their previous quality of life. ${ }^{15,16}$

The clinical symptoms of delirium are wide-ranging. There are hyperactive, hypoactive and mixed forms of delirium. ${ }^{17}$ It is believed that only $10-30 \%$ of all delirium cases are hyperactive, while the mixed type affects about half of patients, and the hypoactive type occurs in $20-40 \%$ of cases. ${ }^{18}$ The elderly patients are generally predisposed to hypoactive delirium. ${ }^{19}$ Overall, better outcomes are associated with hyperactive cases. ${ }^{17}$

Because delirium does not have visible biomarkers, it is difficult to diagnose and can often be overlooked. Given that ICU delirium significantly worsens prognosis and increased mortality, it is vital to investigate this disorder. Hypothetically, the Confusion Assessment Method (CAM) and the Confusion Assessment Method for Intensive Care Unit (CAM-ICU) can serve as excellent tools for identifying delirium predictors. Therefore, this study aimed to diagnose delirium using CAM and CAM-ICU methods and determine the risk factors for its development in senior patients enrolled in the emergency (ED) and intensive care units (ICU) at the National Geriatric Hospital in Vietnam.

\section{Methods}

\section{Study Design}

A cross-sectional observational study was conducted with a convenience sample of non-surgical patients admitted to the ED and ICU at the Hanoi National Geriatric Hospital, Vietnam, between July 2019 and October 2020. The total number of examined patients was 405, but only 163 patients (79 males and 84 females) met the inclusion criteria.

\section{Inclusion Criteria Were as Follows}

- Patients aged $\geq 60$.

- Richmond Agitation Sedation Scale (RASS) score ranging from -4 points.

- $\geq 24$ hours of emergency care.

- Consent from the patient and the patient's family.

\section{Exclusion Criteria Were as Follows}

- Patients who used sedatives while being treated.

- Patients transferred to another Department.

- Neither the research group nor the researchers were able to carry out the evaluation.

- Patients/families were not willing to continue to participate in the research.

The research group included: principal researcher (the author of the study), doctors, nurses in the emergency department at National Geriatrics Hospital, and five medical students. 
After the patients were hospitalized, the research team collected their personal health information, including medical records, clinical characteristics, and information on diagnosis. The following details were obtained as a result (Table 1): demographic and anthropometric data (age, sex, height, and weight), alcohol abuse (frequency per month), smoking habits (pack per year), various comorbidities, use of medication, and results of previous laboratory tests. The functional status of patients was evaluated according to the Barthel Index for Activities of Daily Living (ADL) and the Lawton Instrumental Activities of Daily Living Scale (IADL). Nutritional status was assessed using the Mini Nutritional Assessment Short-Form (MNA-SF). STRATIFY has been used to determine risk factors associated with falling. Frailty syndrome was determined by the Edmonton Frailty Scale. Finally, all patients underwent general blood and biochemical tests and urinalysis.

Table I Demographic and Medical Information Regarding Patients with Delirium $(n=106)$

\begin{tabular}{|l|c|}
\hline Variable & $\begin{array}{c}\text { Patients } \\
\text { (n=106) }\end{array}$ \\
\hline Age: & \\
$60-69$ & $25(23.6 \%)$ \\
$70-79$ & $28(26.4 \%)$ \\
$80-89$ & $36(34.0 \%)$ \\
$\geq 90$ & $17(16.0 \%)$ \\
\hline $\bar{X} \pm$ SD (years old) & $78.3 \pm 10.9$ \\
\hline Sex: & \\
Male & $50(47.2 \%)$ \\
Female & $56(52.8 \%)$ \\
\hline Marital status: & \\
Single & $3(2.8 \%)$ \\
Married & $46(43.4 \%)$ \\
Divorced & $3(2.8 \%)$ \\
Widowed & $54(51.0 \%)$ \\
\hline Living conditions: & \\
Living with Family (Wives/Husbands/ & $73(68.9 \%)$ \\
Children) & $24(22.6 \%)$ \\
Living with caregivers & $7(6.6 \%)$ \\
Living alone & $2(1.9 \%)$ \\
Living in a nursing home & $93(87.7 \%)$ \\
\hline Past medical history associated with delirium: & $86(81.1 \%)$ \\
Vision impairment & $29(27.4 \%)$ \\
Hearing impairment & $75(70.8 \%)$ \\
Smoking & \\
Alcohol consumption & \\
\hline & \\
\hline & \\
\hline & \\
\hline & \\
\hline & \\
\hline
\end{tabular}

The Emergency Department was divided into two treatment areas: an ICU room for severe patients receiving mechanical ventilation and emergency rooms. The patients treated at ED were screened according to the Confusion assessment method (CAM), and patients treated at ICU were screened using the Confusion assessment for the ICU (CAM-ICU). The screening procedure took place every day during the hours of 7 am to 10 am and between $6 \mathrm{pm}$ and $9 \mathrm{pm}$ until discharge. Patients with CAM/CAMICU scores underwent a second assessment for delirium according to Diagnostic and Statistical Manuals of Mental Disorders (DSM-5) and ICD-10. For patients diagnosed with delirium, variables were collected based on the research objectives. The flowchart of the study process is depicted in Figure 1.

\section{Statistical Analysis}

Continuous data are presented as average (with standard deviation) and the percentage number of patients. All variables in patients with delirium versus patients without delirium were analyzed using univariate logistic regression analysis. Statistics were performed by the following methods: the chi-square test, the exact Fisher test, the independent $t$-test, or the Mann-Whitney $U$-test. Differences were considered significant at $\mathrm{P}<0.05$. Risk factors with $\mathrm{P}<0.05$ determined by univariate analysis were included for multiple regression. The C-statistic and the Hosmer-Lemeshow adequacy test were used to evaluate the adequacy of the logistic regression model. All statistical analyses were completed using IBM SPSS Statistics for Windows version 25.0. (IBM Corp., USA).

\section{Ethical Declaration}

This study was carried out in compliance with the Helsinki Declaration and the subsequent modifications. The study design was approved by the Ethics Committee of the National Geriatric Hospital (Protocol No. 123, dated 05/ 18/2019). Study participants and their families or guardians gave written consent to participate.

\section{Results}

Out of 168 patients, 106 (63.1\%) were diagnosed with delirium. Of those, $50(47.2 \%)$ were male, and 56 $(52.8 \%)$ were female patients. The mean age of patients experiencing delirium was $78.3 \pm 10.9$ years. Concerning marital status, $43.4 \%$ of them were married, and $51.0 \%$ were widowed. The majority of patients lived with their families $(68.9 \%)$ or with a guardian $(22.6 \%)$. Vision loss 


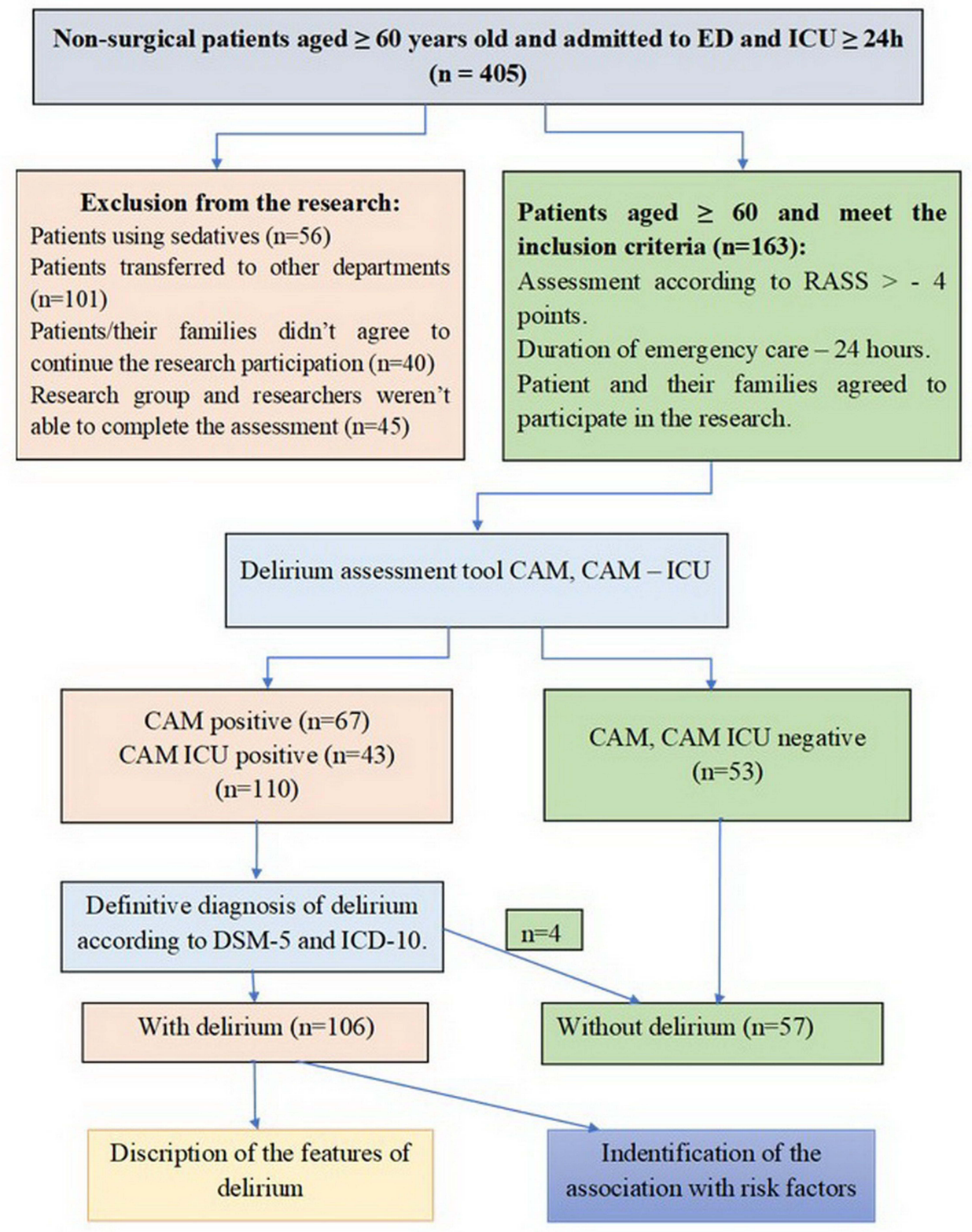

Figure I Study scheme.

occurred in $87.7 \%$ of cases, and hearing loss accounted for $81.1 \%$ of cases. Nearly $70 \%$ of patients consumed alcohol at least monthly, and $27.4 \%$ smoked. Table 1 presents the clinical and demographic characteristics of those diagnosed with delirium.

The distinctive features of CAM/CAM-ICU delirium in patients are presented in Table 2. The most frequent disturbances of consciousness were the impairment of attention concentration ( $81.1 \%$ of patients) and attention retention $(61.3 \%)$. Alteration in cognitive functions manifested as disorientation to place $(89.6 \%)$, time $(89.6 \%)$ and self (55.7\%), immediate memory loss (49.1\%), and loss of short-term memory (49.1\%). Various psychomotor disorders were pronounced: unpredictable transition from one state to another (46\%); increased or decreased speech flow (58.5\%); increased startle response $(50 \%)$. Only five (4.7\%) patients had no sleep disturbances. Mild to moderate daytime sleepiness and sleep disturbances at night were noted in $63.2 \%$ of patients. Severe sleep-wake disturbances (oversleeping or insomnia) and sleep-wake inversion made up 32\% of cases. All patients had emotional disorders, such as depression (33\%), anxiety $(45.2 \%)$, lack of emotion or emotional shock with bewilderment $(20.8 \%)$. Hypoactive delirium was the 
Table 2 Manifestations of Delirium in Patients $(n=106)$

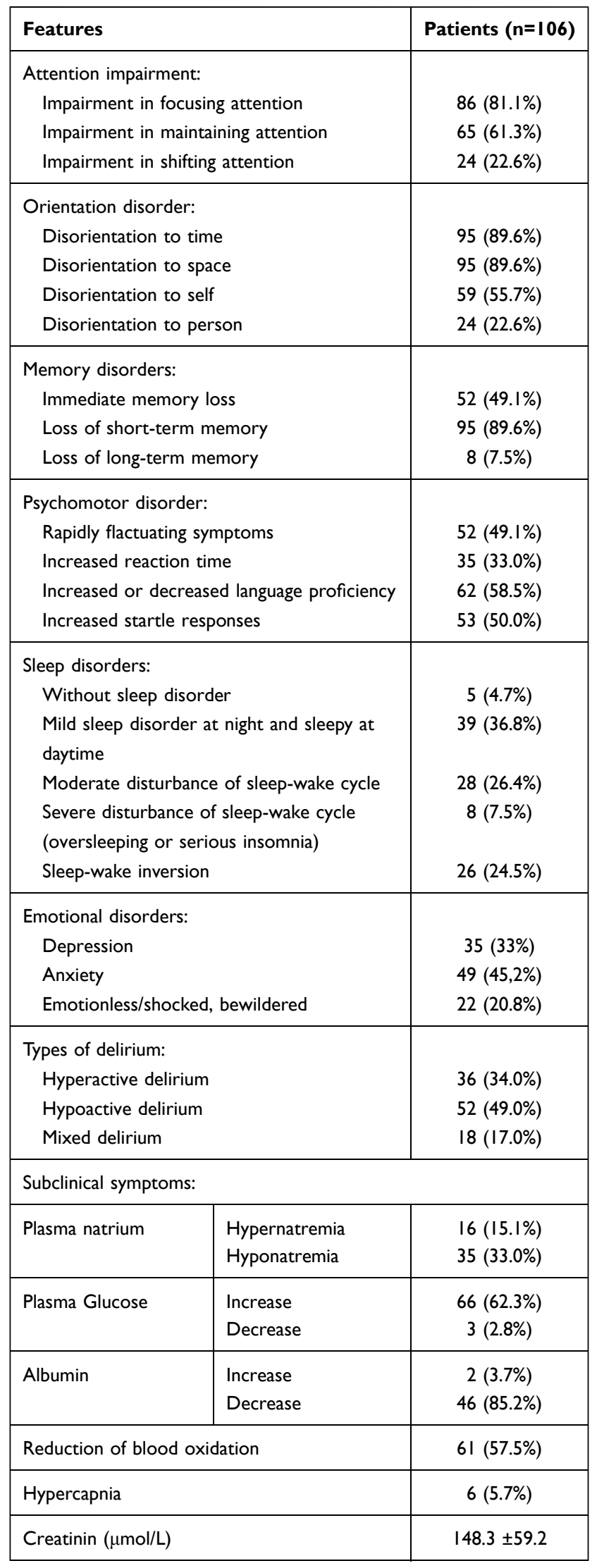

(Continued)
Table 2 (Continued).

\begin{tabular}{|l|c|}
\hline Features & Patients $(\mathbf{n}=106)$ \\
\hline Timing: & $17.9 \pm 34.1$ \\
Time to onset of first symptoms after & \\
admission (hour) & $4.9 \pm 4.9$ \\
\hline Duration of persistence (day) & \\
\hline
\end{tabular}

predominant motor subtype (49\%), followed by hyperactive delirium (34\%) and mixed delirium (17\%).

According to biochemical data, $33.0 \%$ of patients with delirium had hyponatremia, and $15.1 \%$ had hypernatremia. High levels of blood glucose were observed in $62.3 \%$ of cases. Low albumin levels were seen in $85.2 \%$ of patients, and reduced blood oxidation was detected in $57.5 \%$ of cases. Creatinine concentration was high in the majority of patients, reaching an average of $148.3 \pm 59.2 \mu \mathrm{mol} / \mathrm{L}$.

The first symptoms of delirium in patients occurred $17.9 \pm 34.1$ hours after hospitalization and lasted $4.9 \pm 4.9$ days.

The most frequent underlying conditions among patients with delirium (Table 3) were hypertension (67.9\%), pneumonia $(65.1 \%)$, stroke $(41.5 \%)$, diabetes $(40.6 \%)$, anaemia (38.7\%), and kidney dysfunction (31.1\%). On average, there were $4.0 \pm 1.8$ underlying diseases per patient. There were no statistically significant differences in delirium symptoms and underlying diseases between patients in ED and ICU.

The association between delirium and risk factors is depicted in Table 4. The primary predisposing factors were vision impairment (odds ratio [OR], 3.3; 95\% confidence interval $[\mathrm{CI}], 1.5$ to $7.4, \mathrm{P}=0.003$ ), hearing impairment (OR, 3.6; 95\% CI, 1.77 to $7.36, \mathrm{P}=0.0001$ ), and underlying diseases, such as acute/chronic kidney failure (OR, 7.1; 95\% CI, 2.05 to $6.39, \mathrm{P}<0.001$ ) and respiratory disorders (OR, 2.7; 95\% CI, 1.4 to 5.2, $\mathrm{P}=0.004)$. In addition, delirium is related to malnutrition (OR, 9.17; 95\% CI, 3.43-24.5, $\mathrm{P}=0.0001$ ), fall risk (OR, 12.2; 95\% CI, 4.1-36.3, $\mathrm{P}=0.0001$ ), frailty (OR, 8.35; 95\% CI, 3.4-20.6, $\mathrm{P}=0.0001$ ), and activities of daily living on IADLs scale (OR, 8.35; 95\% CI, 3.4-20.6, $\mathrm{P}=0.0001$ ).

According to biochemical findings, electrolytic disturbances were an imperative factor for delirium. Those include hyponatremia (OR, 2.48; 95\% CI, 1.07 to 5.75 , $\mathrm{P}=0.001)$ and hypernatremia (OR, $13.1 ; 95 \% \mathrm{CI}, 1.67$ to 2.5, $\mathrm{P}=0.001$ ). 
Table 3 Underlying Diseases in Patients with Delirium $(n=106)$

\begin{tabular}{|l|c|}
\hline Underlying Diseases & Patients (n= 106) \\
\hline Heart attack & $8(7.5 \%)$ \\
\hline Heart failure & $29(27.4 \%)$ \\
\hline Hypertension & $72(67.9 \%)$ \\
\hline COPD & $13(12.3 \%)$ \\
\hline Pneumonia & $69(65.1 \%)$ \\
\hline Asthma & $5(4.7 \%)$ \\
\hline Lao & $4(3.8 \%)$ \\
\hline Diabetes & $43(40.6 \%)$ \\
\hline Stroke & $44(41.5 \%)$ \\
\hline Kidney disease - kidney failure & $33(31.1 \%)$ \\
\hline Chronic liver disease & $11(10.4 \%)$ \\
\hline Septic shock & $31(29.2 \%)$ \\
\hline Dementia & $19(17.9 \%)$ \\
\hline Cancer & $5(4.7 \%)$ \\
\hline Musculoskeletal disorder & $4(3.8 \%)$ \\
\hline Anaemia & $4.0 \pm 1.8$ \\
\hline Depression & $(2.8 \%)$ \\
\hline Number of underlying diseases in patients with delirium: \\
\hline $\bar{X} \pm$ SD & (3) \\
\hline
\end{tabular}

The most important factors in triggering delirium include interventions in treatment. Those are nasogastric intubation (OR, 6.7; 95\% CI, 1.53 to $3.65, \mathrm{P}=0.004$ ), endotracheal intubation (OR, 3.8; 95\% CI, 1.11 to 2.63, $\mathrm{P}=0.002$ ), urinary catheterization (OR, 7.7; 95\% CI, 1.61 to $4.29, \mathrm{P}<0.001$ ), and invasive mechanical ventilation (OR, 6.3; 95\% CI, 2.05 to 4.48, $\mathrm{P}<0.001$ ).

Note that the duration of ICU admission averaged 12.7 \pm 7.7 days in patients with delirium and $8.5 \pm 4.3$ days in patients without the said condition. Hence, it may also be a triggering factor for this disease (OR, 6.53; 95\% CI, 4.5$25.5, \mathrm{P}<0.0001)$.

\section{Discussion}

In this study, the prevalence of ICU delirium among senior patients was $63.1 \%$. The diagnostic criteria for delirium are outlined in the Diagnostic and Statistical Manual of Mental Disorders (DSM-5). ${ }^{20}$ Those include disturbance of consciousness (ie, reduced clarity of awareness of the environment with inhibited ability to focus, maintain, or shift attention) and changes in cognitive function (ie, memory deficit, disorientation, language disturbance, perceptual disturbance). Disturbance develops over a short period (usually several hours to several days) and tends to fluctuate. There is an apparent relationship with somatic diseases. However, the definition of delirium from a resuscitation perspective is broader than its psychiatric interpretation. In this case, delirium is an acute clinical syndrome, which manifests as a change in the level of consciousness combined with reduced attention or disorganized thought. ${ }^{21}$ Following this interpretation, delirium occurs in $60-80 \%$ of ICU patients, ${ }^{22,23}$ which is consistent with the results of this study. Another factor to consider is that the incidence of delirium is significantly higher in older patients. ${ }^{6}$

In many clinical situations, it is hard to diagnose ICU delirium under the DSM-5 criteria. In particular, it is challenging to assess an intubated patient. For this problem to solve, specific methods of diagnosis were developed, which resuscitators can exploit efficiently in their routine practice. ${ }^{24}$

These methods are based on several fundamental aspects that distinguish delirium from other conditions. First, delirium is an exclusively clinical syndrome and can be diagnosed by clinical examination without additional laboratory or instrumental methods. Second, it develops over a short period of time (several hours to several days) and follows some kind of stress (eg, surgery, trauma, acute infection process, or pain syndrome). Third, it always manifests as a change in the level of consciousness. Fourth, consideration should be given to measuring the level of attention. Two types of attention disorders can be distinguished: difficulty in focusing attention and inability to maintain it. Fifth, the diagnosis involves the assessment of a disorganized thought process. The above steps align with the CAM/CAM-ICU algorithm for diagnosing delirium.

The diagnosis of delirium in the present study was based on the above principles. Thus, symptoms of delirium in participating patients emerged $17.9 \pm 34.1$ hours after ICU admission. The condition lasted $4.9 \pm 4.9$ days. Patients exhibited reduced attention and inability to maintain it, disorientation to time and space, decreased memory, speech impairment, and loss of awareness of the environment. 
Table 4 Association of Delirium and Risk Factors

\begin{tabular}{|c|c|c|c|c|c|c|}
\hline \multicolumn{2}{|l|}{ Risk factors } & With Delirium $(n=106)$ & Without Delirium $(n=57)$ & OR & $95 \% \mathrm{Cl}$ & $\mathbf{P}$ \\
\hline \multicolumn{7}{|c|}{ Sensory impairment, substance use history: } \\
\hline \multicolumn{2}{|l|}{ Vision impairment } & $93(87.7 \%)$ & 39 (68.4\%) & 3.3 & $1.5-7.4$ & 0.003 \\
\hline \multicolumn{2}{|l|}{ Hearing impairment } & $86(81.1 \%)$ & 31 (54.4\%) & 3.6 & $1.77-7.36$ & 0.0001 \\
\hline \multicolumn{2}{|l|}{ Smoking } & $29(27.4 \%)$ & $12(21.1 \%)$ & 1.4 & $0.3-1.5$ & 0.37 \\
\hline \multicolumn{2}{|l|}{ Alcohol consumption } & $75(70.8 \%)$ & $39(68.4 \%)$ & 1.6 & $0.4-1.7$ & 0.7 \\
\hline \multicolumn{7}{|l|}{ Interventions in treatment: } \\
\hline \multicolumn{2}{|l|}{ Nasogastric intubation } & $21(19.8 \%)$ & $2(3.5 \%)$ & 6.7 & $1.53-3.65$ & 0.004 \\
\hline \multicolumn{2}{|l|}{ Urinary catheterization } & $60(56.6 \%)$ & $8(24.0 \%)$ & 7.7 & $1.61-4.29$ & $<0.001$ \\
\hline \multicolumn{2}{|l|}{ Endotracheal intubation } & 37 (34.9\%) & 7 (22.3\%) & 3.8 & $1.11-2.63$ & 0.002 \\
\hline \multicolumn{2}{|l|}{ Tracheostomy } & $10(8.9 \%)$ & $0(0 \%)$ & 1.6 & $1.4-1.8$ & 0.015 \\
\hline \multicolumn{2}{|c|}{ Invasive mechanical ventilation } & $34(32.1 \%)$ & $4(7.0 \%)$ & 6.3 & $2.05-4.48$ & $<0.001$ \\
\hline \multicolumn{7}{|c|}{ Electrolyte disturbance, glucose disturbance: } \\
\hline \multirow[t]{2}{*}{ Plasma natrium (mmol/L) } & $\begin{array}{l}\text { Hyponatremia }[\mathrm{Na}]< \\
\text { I } 35\end{array}$ & $35(33.0 \%)$ & I (I.75\%) & 2.48 & $1.07-5.75$ & \multirow[t]{2}{*}{0.001} \\
\hline & $\begin{array}{l}\text { Hypernatremia }[\mathrm{Na}]: \\
>145\end{array}$ & $16(15.1 \%)$ & I (I.75\%) & 13.1 & $1.67-2.5$ & \\
\hline \multicolumn{2}{|l|}{ Glucose $\leq 7.8 \mathrm{mmol} / \mathrm{l}$} & $45(42.5 \%)$ & 31 (54.4\%) & 1 & \multirow[t]{2}{*}{$0.84-3.1$} & \multirow[t]{2}{*}{0.14} \\
\hline \multicolumn{2}{|l|}{ Glucose $>7.8 \mathrm{mmol} / \mathrm{l}$} & $66(62.3 \%)$ & $26(45.6 \%)$ & 1.6 & & \\
\hline \multicolumn{7}{|c|}{ Nutritional status (scale MNA - SF): } \\
\hline \multicolumn{2}{|c|}{ 12-14 points: normal nutrition } & $12(11.3 \%)$ & $20(35.1 \%)$ & 1 & - & \multirow[t]{4}{*}{0.0001} \\
\hline \multicolumn{2}{|c|}{ 8-II points: risk of malnutrition } & $38(35.8 \%)$ & 27 (47.4\%) & 2.35 & $0.98-5.59$ & \\
\hline \multicolumn{2}{|l|}{$0-7$ points: malnutrition } & $56(52.9 \%)$ & $10(17.5 \%)$ & 9.17 & $3.43-24.5$ & \\
\hline \multicolumn{2}{|l|}{ Mean of MNA \pm SD } & $2.39 \pm 0.73$ & $1.82 \pm 0.09$ & & & \\
\hline \multicolumn{7}{|c|}{ Fall Risk Factors (Stratify Scale): } \\
\hline \multicolumn{2}{|l|}{0 point: low risk of fall } & $5(4.7 \%)$ & 18 (3I.6\%) & I & - & \multirow[t]{3}{*}{0.0001} \\
\hline \multicolumn{2}{|c|}{ I point: moderate risk of fall } & $16(15.1 \%)$ & 14 (24.6\%) & 4.1 & $4.2-14$ & \\
\hline$\geq 2$ point: high risk of fall & & $85(80.2 \%)$ & 25 (43.8\%) & 12.2 & $4.1-36.3$ & \\
\hline Pain: & & & & & & \\
\hline Yes & & $10(9.4 \%)$ & $6(10.5 \%)$ & 1 & $0.3-2.6$ & 0.82 \\
\hline No & & $96(90.6 \%)$ & 51 (89.5\%) & 1.12 & & \\
\hline Drug use: & & & & & & \\
\hline Benzodiazepine & & $13(12.3 \%)$ & $4(7.0 \%)$ & 1.9 & $0.1-1.7$ & 0.3 \\
\hline Opioid & & $2(1.9 \%)$ & $0(0 \%)$ & 1.5 & $1.4-1.7$ & 0.3 \\
\hline Corticoid & & $18(17.0 \%)$ & $4(7.0 \%)$ & 2.7 & $0.1-1.1$ & 0.08 \\
\hline
\end{tabular}


Table 4 (Continued).

\begin{tabular}{|c|c|c|c|c|c|c|}
\hline \multicolumn{2}{|l|}{ Risk factors } & \multirow{3}{*}{$\begin{array}{l}\text { With Delirium }(n=106) \\
16(15.1 \%) \\
90(84.9 \%)\end{array}$} & \multirow{3}{*}{$\begin{array}{l}\text { Without Delirium }(n=57) \\
18(31.6 \%) \\
39(68.4 \%)\end{array}$} & \multirow{3}{*}{$\begin{array}{l}\text { OR } \\
1 \\
2.6\end{array}$} & \multirow{3}{*}{$\begin{array}{l}95 \% \mathrm{Cl} \\
1.2-5.6\end{array}$} & \multirow{3}{*}{$\begin{array}{c}\mathbf{P} \\
0.014\end{array}$} \\
\hline \multirow[t]{2}{*}{ Total number of drugs per patient } & $<5$ & & & & & \\
\hline & $\geq 5$ & & & & & \\
\hline \multicolumn{7}{|l|}{ Duration of admission: } \\
\hline \multicolumn{2}{|l|}{ Days $(\bar{X} \pm \mathrm{SD})$} & $12.7 \pm 7.7$ & $8.5 \pm 4.3$ & 5.7 & $0.6-2.3$ & $<0.001$ \\
\hline \multicolumn{7}{|c|}{ Past medical history of stroke, dementia: } \\
\hline \multicolumn{2}{|l|}{ Stroke } & $23(21.7 \%)$ & $4(7.0 \%)$ & 3.7 & $0.09-0.83$ & 0.016 \\
\hline \multicolumn{2}{|l|}{ Dementia } & $16(15.1 \%)$ & $3(5.3 \%)$ & 3.2 & $0.09-1.12$ & 0.62 \\
\hline \multicolumn{7}{|l|}{ Age: } \\
\hline \multicolumn{2}{|l|}{$<65$ years old } & $14(13.2 \%)$ & $6(10.5 \%)$ & 1 & \multirow[t]{2}{*}{$0.3-2.14$} & \multirow[t]{2}{*}{0.62} \\
\hline \multicolumn{2}{|l|}{$\geq 65$ years old } & $92(86.8 \%)$ & $5 \mathrm{I}(89.5 \%)$ & 1.3 & & \\
\hline \multicolumn{7}{|l|}{ Gender: } \\
\hline \multicolumn{2}{|l|}{ Female } & $50(47.2 \%)$ & $29(50.9 \%)$ & 1 & \multirow[t]{2}{*}{$0.6 \mathrm{I}-2.2 \mathrm{I}$} & \multirow[t]{2}{*}{0.65} \\
\hline \multicolumn{2}{|l|}{ Male } & $56(52.8 \%)$ & $28(49.1 \%)$ & 1.16 & & \\
\hline \multicolumn{7}{|l|}{ Several accompanying conditions: } \\
\hline \multicolumn{2}{|c|}{ Acute kidney failure or chronic kidney failure } & $43(40.6 \%)$ & $5(8.8 \%)$ & 7.1 & $2.05-6.39$ & $<0.001$ \\
\hline \multicolumn{2}{|l|}{ Respiratory failure } & $67(63.2 \%)$ & $22(40.4 \%)$ & 2.7 & $1.4-5.2$ & 0.004 \\
\hline \multicolumn{2}{|c|}{ Acute liver failure and chronic liver failure } & $\mathrm{II}(10.4 \%)$ & $6(10.5 \%)$ & 1.02 & $0.3-2.9$ & 0.98 \\
\hline \multicolumn{2}{|l|}{ Number of accompanying pathologies } & $4.0 \pm 1.7$ & $2.9 \pm 1.3$ & & & $<0.001$ \\
\hline \multicolumn{7}{|c|}{ Frailty Syndrome (Edmonton Frail Scale): } \\
\hline \multicolumn{2}{|l|}{$<5$ points: without frailty syndrome } & $17(16.0 \%)$ & $33(57.9 \%)$ & 1 & - & \multirow[t]{6}{*}{0.0001} \\
\hline \multicolumn{2}{|l|}{ 6-7 points: risk of frailty syndrome } & $13(12.3 \%)$ & $7(12.3 \%)$ & 3.6 & $1.2-10.7$ & \\
\hline \multicolumn{2}{|l|}{ 8-9 points: mild frailty } & $17(16.0 \%)$ & $6(10.5 \%)$ & 5.5 & $1.8-16.5$ & \\
\hline I0-II points: moderate frailty & & $16(15.1 \%)$ & $\mathrm{I}(\mathrm{I} .8 \%)$ & 3.1 & $3.8-25.4$ & \\
\hline 12-17 points: severe frailty & & $43(40.6 \%)$ & $10(17.5 \%)$ & 8.35 & $3.4-20.6$ & \\
\hline REFS mean $\pm S D$ & & $9.7 \pm 3.8$ & $5.8 \pm 4.3$ & & & \\
\hline Activities of daily living scale (IADL & & & & & & \\
\hline Mean of $A D L$ point $\pm S D$ & & $2.5 \pm 2.1$ & $4.2 \pm 2.1$ & 6.53 & $4.5-25.5$ & 0.0001 \\
\hline
\end{tabular}

In most cases, it was hard to identify a single cause of delirium. The reason is the multifactorial aetiology of this disease. Typically, there are two to six reasons behind it. ${ }^{25}$ Seeking and naming a single cause is a simplification: every case requires a detailed re-analysis of multiple possible factors. Generally, scholars distinguish 60 risk factors for delirium in older patients. ${ }^{26}$
The contributory factors for delirium are physical fixation, malnutrition, administration of more than three drugs, bladder catheterization, and iatrogenic phenomena. ${ }^{27,28} \mathrm{In}$ elderly patients, predictors for developing delirium include visual impairment, cognitive impairment, and BUN/creatinine ratio $\geq 18 \mu \mathrm{mol} / \mathrm{L}$. Other risk factors are the preoperative use of narcotics or benzodiazepines and alcohol 
abuse. $^{29}$ Smoking and atherosclerotic vascular disorders also play a role in the development of delirium. ${ }^{30}$

Typical risk factors for delirium include dementia and infectious complications. ${ }^{31}$ Dementia, for instance, increases the risk of developing delirium six times, while with benzodiazepine, the change of delirium occurring is just three times higher. ${ }^{32}$

Based on the review of studies on ICU delirium risk factors, ${ }^{31,33-37}$ it is reasonable to divide them into three groups: 1) premorbid factors (demographic factors and underlying diseases), 2) acutely developing conditions, and 3) medications or interventions during treatment. The first group includes predisposing factors (for the most part), while the second and third groups embrace the triggers. The most common premorbid factors are being aged over 70 years, living in a nursing home, visual and/or hearing impairment, depressive disorders, dementia, congestive heart failure, renal failure, liver failure, use of psychotropic drugs, and malnutrition. In this study, delirium was linked to visual and hearing impairments, as well as malnutrition (MNA-SF). No correlation was found between delirium and the age of patients. However, there was a statistically significant association of delirium with frailty (Edmonton Frail Scale) and fall risk factors (Stratify Scale). This trend may indicate higher importance of biological, rather than calendar, age. It was not possible to establish a link between delirium and living in a nursing home, as only two patients were enrolled in such places. The percentage of widowed subjects was higher among patients with delirium than those without it, although the difference was not statistically significant. There were no sex-based differences between patients with or without delirium.

A statistically significant association was found between delirium and underlying diseases, such as acute kidney failure, chronic kidney failure, and respiratory failure. Furthermore, there was a statistically significant relationship with the number of accompanying diseases.

The second group of risk factors includes hypo/hyperglycemia, hypo/hypernatremia, hypo/hyperthyroidism, hypothermia, fever, severe infection, sepsis, hypoxemia, severe pain syndrome, and BUN/creatinine ratio $\geq 18 \mu \mathrm{mol} / \mathrm{L}$. Of those factors, delirium correlated with hypo/hypernatremia.

The third group of risk factors encompasses the use of medications with anticholinergic, dopaminergic, sedative, and narcotic effects and treatment interventions (eg, physical fixation, tube feeding, urinary catheter, gas tube, central venous catheter). The present study failed to establish a statistically significant association between medication intake and delirium. Treatment interventions, however, were not the case. The results revealed a strong relationship with these interventions: nasogastric intubation, urinary catheterization, endotracheal intubation, and invasive mechanical ventilation.

Overall, the present study confirmed the role of some previously discussed factors ${ }^{20-24,31,34-37}$ in the development of ICU delirium in elderly patients. At the same time, the study has several limitations that should be noted. First, the study sample includes non-surgical patients, not to mention that the sample size is small. Second, studies took place in just one medical institution. The focus was limited to the relationship between delirium and risk factors. The nature and size of the sample do not allow identifying all significant associations with delirium.

\section{Conclusion}

Delirium can be successfully diagnosed using the CAM/ CAM-ICU diagnostic algorithm. The aetiology of delirium is multifactorial, meaning that a single cause cannot be identified. The present study provided evidence on the role of some predisposing and triggering factors in the occurrence of delirium in senior patients in ED and ICU. Risk factors for developing delirium in ED and ICU patients were divided into three groups: 1) premorbid factors; 2) acutely developing conditions; 3) medicines and medical procedures. As regards factors in group 1, delirium was related to impaired vision and hearing, malnutrition, frailty, and fall risk factors. There was also a statistically significant association between delirium and acute renal failure, chronic renal failure, respiratory failure, and comorbidity count. A strong relationship was seen between delirium and hypo/hypernatremia (group 2 factor). Finally, the paper revealed a statistically significant association with these group 3 factors: nasogastric intubation, urine catheterization, tracheal intubation, and invasive mechanical ventilation. There is a need to dwell further into risk factors for delirium in elderly patients.

\section{Data Sharing Statement}

Data will be available on request.

\section{Ethics Approval and Informed Consent}

This study was carried out in compliance with the ethical requirements of the Helsinki Declaration and all 
subsequent supplements. The study protocol was approved by the National Geriatric Hospital Ethics Committee. All participants gave informed consent.

\section{Consent for Publication}

Written consent was provided by the study participants and their families or guardians.

\section{Author Contributions}

All authors contributed to data analysis, drafting or revising the article, gave final approval of the version to be published, agreed to the submitted journal, and agree to be accountable for all aspects of the work.

NNT - Conception and design, Provision of study materials or patients, Data analysis and interpretation, Manuscript writing, Final approval of manuscript; TPNH - Administrative support, Provision of study materials or patients, Collection and assembly of data, Manuscript writing, Final approval of manuscript; TKTH - Administrative support, Conception and design, Collection and assembly of data, Manuscript writing, Final approval of manuscript.

\section{Funding}

This research did not receive any specific grant from funding agencies in the public, commercial, or not-forprofit sectors.

\section{Disclosure}

The authors report no conflicts of interest in this work.

\section{References}

1. McPherson JA, Wagner CE, Boehm LM, et al. Delirium in the cardiovascular intensive care unit: exploring modifiable risk factors. Crit Care Med. 2013;41(2):405-413. doi:10.1097/CCM.0b013e3182 $6 \mathrm{ab} 49 \mathrm{~b}$

2. Hayhurst CJ, Pandharipande PP, Hughes CG. Intensive care unit delirium: a review of diagnosis, prevention, and treatment. Anesthesiology. 2016;125(6):1229-1241. doi:10.1097/ALN.00000000 00001378

3. Kotfis K, Marra A, Ely EW. ICU delirium - a diagnostic and therapeutic challenge in the intensive care unit. Anaesthesiol Intensive Ther. 2018;50(2):160-167. doi:10.5603/AIT.a2018.0011

4. Chen TJ, Chung YW, Chang HR, et al. Diagnostic accuracy of the CAM-ICU and ICDSC in detecting intensive care unit delirium: a bivariate meta-analysis. Int J Nurs Stud. 2021;113:103782. doi:10.1016/j.ijnurstu.2020.103782

5. Singler K, Thomas C. HELP-hospital elder life program a multimodal intervention program for prevention of delirium in elderly patients. Internist. 2017;58(2):125-131. doi:10.1007/s00108016-0181-0

6. Hshieh TT, Inouye SK, Oh ES. Delirium in the elderly. Psychiatr Clin North Am. 2018;41(1):1-17. doi:10.1016/j.psc.2017.10.001
7. Rengel KF, Pandharipande PP, Hughes CG. Postoperative delirium. Presse Med. 2018;47(4):53-64. doi:10.1016/j.lpm.2018.03.012

8. Kotekar N, Shenkar A, Nagaraj R. Postoperative cognitive dysfunctioncurrent preventive strategies. Clin Interv Aging. 2018;13:2267-2273. doi:10.2147/CIA.S133896

9. Glumac S, Kardum G, Karanovic N. Postoperative cognitive decline after cardiac surgery: a narrative review of current knowledge in 2019. Med Sci Monit. 2019;3(25):3262-3270. doi:10.12659/ MSM.914435

10. Sepulveda E, Franco JG, Trzepacz PT, et al. Delirium diagnosis defined by cluster analysis of symptoms versus diagnosis by DSM and ICD criteria: Diagnostic Accuracy Study. BMC Psychiatry. 2016;16(1):167. doi:10.1186/s12888-016-0878-6

11. Wassenaar A, van den Boogaard MHWA, van Achterberg T, et al. Multinational development and validation of an early prediction model for delirium in ICU patients. Inten Care Med. 2015;41 (6): 1048-1056. doi:10.1007/s00134-015-3777-2

12. Li Y, Yuan D, Li X, Wang S. Risk factors for delirium in intensive care unit and its duration. Zhonghua Wei Zhong Bing Ji Jiu Yi Xue. 2020;32(1):62-66.

13. Kanova M, Sklienka P, Kula R, Burda M, Janoutova J. Incidence and risk factors for delirium development in ICU patients-a prospective observational study. Biomed Pap Med Fac Univ Palacky Olomouc Czech Repub. 2017;161(2):187-196. doi:10.5507/bp.2017.004

14. Yang Y, Zhao X, Dong T, Yang Z, Zhang Q, Zhang Y. Risk factors for postoperative delirium following hip fracture repair in elderly patients: a systematic review and meta-analysis. Aging Clin Exp Res. 2017;29(2):115-126. doi:10.1007/s40520-016-0541-6

15. Norman BC, Jackson JC, Graves JA, et al. Employment outcomes after critical illness: an analysis of the BRAIN-ICU cohort. Crit Care Med. 2016;44(11):2003-2009. doi:10.1097/CCM.0000000000 001849

16. Hayhurst CJ, Marra A, Han JH, et al. Association of hypoactive and hyperactive delirium with cognitive function after critical illness. Crit Care Med. 2020;48(6):480-488. doi:10.1097/CCM.000000000 0004313

17. van Velthuijsen EL, Zwakhalen SM, Mulder WJ, Verhey FRJ, Kempen GIJM. Detection and management of hyperactive and hypoactive delirium in older patients during hospitalization: a Retrospective Cohort Study evaluating daily practice. Int J Geriatr Psychiatry. 2018;33(11):1521-1529. doi:10.1002/ gps. 4690

18. Maschke M. Ursachen und Therapie des Delirs. Dtsch Med Wochenschr. 2019;144(2):101-107. doi:10.1055/s-0043-109380

19. Kumar A, Bakhla AK, Gupta S, Raju BMSVK, Prasad A. Etiologic and cognitive differences in hyperactive and hypoactive delirium. Prim Care Companion CNS Disord. 2015;17(6):1-9.

20. Yermilova V, Stroiteleva N, Egorova Z, Vanina E. The impact of harmful habits on academic performance and sports activities among young people. J Intellect Disabil Diagn Treat. 2021;9(3):267-273. doi:10.6000/2292-2598.2021.09.03.2

21. Su X, Meng ZT, Wu XH, et al. Dexmedetomidine for prevention of delirium in elderly patients after non-cardiac surgery: a randomised, double-blind, placebo-controlled trial. Lancet. 2016;388 (10054):1893-1902. doi:10.1016/S0140-6736(16)30580-3

22. Vasilevskis EE, Chandrasekhar R, Holtze CH, et al. The cost of ICU delirium and coma in the intensive care unit patient. Med Care. 2018;56(10):890 - 897. doi:10.1097/MLR.0000000000000975

23. Marra A, Kotfis K, Hosie A, et al. Delirium monitoring: yes, or no? That is the question. Am $J$ Crit Care. 2019;28(2):127-135. doi:10.4037/ajcc2019874

24. Adamis D, Meagher D, Rooney S, Mulligan O, McCarthy G. A comparison of outcomes according to different diagnostic systems for delirium (DSM-5, DSM-IV, CAM, and DRS-R98). Int Psychogeriatr. 2018;30(4):591-596. doi:10.1017/S104161021700 1697 
25. Marcantonio ER. Delirium in hospitalized older adults. $N$ Engl $J$ Med. 2017;377(15):1456-1466. doi:10.1056/NEJMcp1605501

26. De J, Wand AP. Delirium screening: a systematic review of delirium screening tools in hospitalized patients. Gerontologist. 2015;55 (6):1079-1099. doi:10.1093/geront/gnv100

27. Zipser CM, Deuel J, Ernst J, et al. Predisposing and precipitating factors for delirium in neurology: a Prospective Cohort Study of 1487 patients. J Neurol. 2019;266(12):3065-3075. doi:10.1007/s00415019-09533-4

28. O'Regan NA, Fitzgerald J, Adamis D, Molloy DW, Meagher D, Timmons S. Predictors of delirium development in older medical inpatients: readily identifiable factors at admission. J Alzheimers Dis. 2018;64(3):775-785. doi:10.3233/JAD-180178

29. Zaal IJ, Devlin JW, Peelen LM, Slooter AJ. A systematic review of risk factors for delirium in the ICU. Crit Care Med. 2015;43 (1):40-47. doi:10.1097/CCM.0000000000000625

30. Rieck KM, Pagali S, Miller DM. Delirium in hospitalized older adults. Hosp Pract. 2020;48(sup1):3-16. doi:10.1080/21548331. 2019.1709359

31. Van Gool WA, Van de Beek D, Eikelenboom P. Systemic infection and delirium: when cytokines and acetylcholine collide. Lancet. 2010;375(9716):773-775. doi:10.1016/S0140-6736(09)61158-2
32. Li Y, Ma J, Jin Y, et al. Benzodiazepines for treatment of patients with delirium excluding those who are cared for in an intensive care unit. Cochrane Database Syst Rev. 2020;2(2):CD012670.

33. Choi S, Jung I, Yoo B, Lee S, Kim MC. Risk factors for postoperative delirium in elderly patients after spinal fusion surgery. Anesth Pain Med. 2020;15(3):275-282. doi:10.17085/apm.19092

34. Iamaroon A, Wongviriyawong T, Sura-Arunsumrit P, Wiwatnodom N, Rewuri N, Chaiwat O. Incidence of and risk factors for postoperative delirium in older adult patients undergoing noncardiac surgery: a Prospective Study. BMC Geriatr. 2020;20(1):40. doi:10.1186/s12877-020-1449-8

35. Su L, Yan Y, Huang W, et al. Risk factors for intensive care unit delirium after cardiac operation. Zhonghua Wei Zhong Bing Ji Jiu Yi Xue. 2019;31(2):165-171.

36. van der Sluis FJ, Buisman PL, Meerdink M, et al. Risk factors for postoperative delirium after colorectal operation. Surgery. 2017;161 (3):704-711. doi:10.1016/j.surg.2016.09.010

37. Wang CG, Qin YF, Wan X, Song LC, Li ZJ, Li H. Incidence and risk factors of postoperative delirium in the elderly patients with hip fracture. J Orthop Surg Res. 2018;13(1):186. doi:10.1186/s13018018-0897-8
International Journal of General Medicine

\section{Publish your work in this journal}

The International Journal of General Medicine is an international, peer-reviewed open-access journal that focuses on general and internal medicine, pathogenesis, epidemiology, diagnosis, monitoring and treatment protocols. The journal is characterized by the rapid reporting of reviews, original research and clinical studies

\section{Dovepress}

across all disease areas. The manuscript management system is completely online and includes a very quick and fair peer-review system, which is all easy to use. Visit http://www.dovepress.com/ testimonials.php to read real quotes from published authors. 